\title{
VÍAS PREHISPÁNICAS Y CULTO DE LOS MUERTOS EN EL NORTE CHILENO (ARICA-TARAPACÁ) DURANTE EL PERÍODO INTERMEDIO TARDÍO Y EL HORIZONTE TARDÍO (CA. 1.000-1.532 D.C.)*
}

\author{
PREHISPANIC ROADS AND ANCESTOR WORSHIP IN NORTHERN CHILE \\ (ARICA-TARAPACÁ) DURING THE LATE INTERMEDIATE PERIOD \\ AND LATE HORIZON (CA. 1,000-1,532 AD)
}

\author{
Erwan Duffait ${ }^{1}$
}

\begin{abstract}
Este artículo ofrece los resultados del estudio de algunas vías prehispánicas del norte chileno (Arica-Tarapacá). Un nuevo tramo de $10 \mathrm{~km}$ identificado entre Belén y el valle de Azapa presenta evidencias constructivas con muros de contención y pavimento. Este trabajo estudia las características técnicas de las vías y analiza los vínculos estrechos entre los caminos y el paisaje sagrado salpicado por elementos ligados a la memoria colectiva de las poblaciones andinas y especialmente al culto de los ancestros.

Palabras claves: norte chileno, inca, vías, etnohistoria, paisaje, culto de los ancestros.
\end{abstract}

This paper presents an outline of study of some prehispanic roads in northern Chile (Arica-Tarapacá). A new road section of $10 \mathrm{~km}$ discovered between Belén and the Azapa valley has architectural elements such as retention walls and pavement. This work studies the technical characteristics of the routes and analyzes the links between roads and sacred landscape splashed by elements tied to the collective memory of the Andean populations and especially to the worship of the ancestors.

Key words: Northern Chile, inca, roads, ethnohistory, landscape, worship of the ancestors.

A la llegada de los españoles a la cordillera de los Andes, el Tawantinsuy u tenía una superficie de aproximadamente $1.000 .000 \mathrm{~km}^{2}$ y una población de 10.000.000 habitantes (Pärssinen 2003:239; Wachtel 1971:140). A fin de manejar los recursos y la mano de obra de este amplio territorio, los incas reutilizaron y mejoraron la red vial ya existente (López de Gómara 1946 [1552]:277; Regal 1936:6-7) y construyeron diferentes tipos de asentamientos. Las chaskihuasi eran postas permitiendo la circulación rápida de las noticias entre Cusco y la administración inca provincial. Los tampu, ubicados a aproximadamente un día de caminata uno de otro, eran posadas con depósitos destinados principalmente al abastecimiento de la burocracia inca. Por fin, los incas habían construido centros administrativos regionales ubicados a cada tres-cinco días de caminata los unos de los otros, y tenían capacidades de almacenamiento mucho mayor que los tampu. Se trataba de centenas de depósitos para abastecer al ejército y las poblaciones locales en el marco de la reciprocidad y la redistribución (Betanzos 1999 [1551]:108; Cieza de León 1996 [1553]:60; Cobo 1964 [1653]II:129; Estete 1891 [1534]:121-149; González Holguín 1608:173,191; Hyslop 1992 [1984]:176,188-199; Murra 1956:207).

Por supuesto, fuera del aspecto administrativo y político las vías tenían otras funciones: militares, económico-religiosas y ceremoniales. Como lo subraya Hyslop (1984:340-343) en las últimas páginas de su obra sobre la red vial inca, los caminos tenían una función simbólica e ideológica. Expresaban la geografía cultural y estaban investidos de un importante significado ritual y es este aspecto en particular el que nos interesa en el presente artículo. En esta perspectiva y cualquiera que sea el aspecto de las vías (tramos pavimentados o simples senderos de tierra), se necesita tomar en cuenta todos los elementos del paisaje (cerros, nevados, volcanes, rocas, cuevas, ríos, lagunas,

\footnotetext{
* Artículo proyecto ECOS-CONICYT Dinámicas culturales en el Área Centro Sur Andina. Código C06H04 y PICS 4796.

1 Universidad Paris 1 Panthéon-Sorbonne, Francia. erwanduffait@yahoo.fr
} 
fuentes, árboles...) asociados o visibles desde los caminos. Efectivamente, estos elementos tenían una función ceremonial y simbólica importante ligada a la memoria colectiva y los orígenes -reales o míticos- de las diversas comunidades andinas, como bien se sabe (Duviols 1967:20, 1971:255). Hasta el día de hoy las vías de comunicación andinas fueron estudiadas principalmente bajo sus aspectos técnicos, mientras que sus funciones simbólicas relacionadas con el paisaje y el culto de los ancestros han sido poco tratadas. En este artículo abordaré el fenómeno religioso del culto de los muertos a través del estudio de la red vial prehispánica del norte chileno (Arica y Tarapacá) durante el período Intermedio Tardío y el Horizonte Tardío (ca. 1.000-1.532 d.C.). Después de la presentación de la zona de estudio y de los trabajos anteriores, se describen las características técnicas de algunas de las vías que recorrí a pie $(200 \mathrm{~km})$ en la precordillera de Arica y en los valles de Azapa y Tarapacá. Por fin, se procederá al análisis de la red vial de este territorio y especialmente su integración en el paisaje sagrado vinculado con el culto de los volcanes aproximándonos a la noción de pacarina.

\section{La Geografía del Norte Chileno}

El territorio chileno que constituye nuestra zona de estudio se extiende entre el $18^{\circ}$ y el $20^{\circ}$ de latitud sur y el océano Pacífico al oeste. El norte chileno incluye dos áreas muy distintas: las tierras bajas de la costa desértica y las tierras altas de la cordillera de los Andes. La zona costera constituye una banda estrecha $(50-100 \mathrm{~km})$ de mesetas con pendientes suaves subiendo hacia la cordillera. Estas mesetas son cortadas por valles-oasis donde se practica la agricultura y se concentran las poblaciones humanas desde varios milenios. La cordillera cuenta con varios volcanes: el Tacora (5.980 msm), el Tarapacá (5.815 msm), el Parinacota $(6.330 \mathrm{msm})$, el Pomerape $(6.230 \mathrm{msm})$, el Guallatiri $(6.060 \mathrm{msm})$ y el Isluga $(5.530 \mathrm{msm})$ (Reinhard 2002). Del lado boliviano, a pocos kilómetros de la frontera chilena, se encuentran los volcanes Sajama (6.540 msm) y Tata Sabaya $(5.430 \mathrm{msm})$. Desde Arica hasta Pisagua los ríos, a menudo intermitentes, tienen un curso este-oeste y desembocan en el océano Pacífico. Más al sur, entre Pisagua y el río Loa, una cordillera costera poco elevada impide que corran los ríos hasta el mar. La característica principal de la costa desértica es su extrema aridez y la presencia de pocos recursos de agua. Durante la época invernal (mayo-octubre) la neblina llamada camanchaca permite el desarrollo de plantas y pastos. La cordillera de los Andes tiene mayores recursos de agua, especialmente durante la época de lluvias (noviembre-abril). La vegetación de la cordillera es xerófita y representada mayormente por la tola (Parastrephia sp.) y el ichu (Stipa ichu) que constituyen con los bofedales los principales alimentos de los camélidos domesticados y salvajes.

En la cordillera predomina la cultura de los tubérculos (papas, ocas, ollucos) y de las gramíneas como la quinoa y la kiwicha. Aunque la extrema aridez del norte chileno limite el desarrollo de la agricultura, las tierras de los valles-oasis $(<2.500 \mathrm{msm})$ permiten el cultivo de varias plantas: coca, ají, fríjol, maíz, algodón, cucurbitáceas... Los recursos marinos constituyen un aporte nutricional significativo en la dieta de las poblaciones costeras. Desde épocas muy remotas estos productos y el guano de las aves marinas han sido intercambiados con los grupos de la cordillera. Los incas controlaban estrechamente el guano utilizado como fertilizante en las tierras agrícolas (Cieza de León 1988 [1553]:222-223; Julien 1985; Vázquez de Espinosa 1969 [1628]:346,348). Los recursos de mayor interés en todo el norte chileno lo constituyen los yacimientos mineros que tenían una función religiosa y simbólica muy importante para las poblaciones prehispánicas (Berthelot 1977; Bouysse-Cassagne 1997). Muchas crónicas indican que los incas conquistaron el territorio chileno a fin de controlar sus riquezas minerales (Betanzos 1999 [1551]:148; Cieza de León 1996 [1553]:176,183; Sarmiento de Gamboa 2001 [1572]:131). Según Pizarro (1944 [1571]:150-152) y Cobo (1964 [1653]II:131), las minas de plata de Huantajaya, cerca de Iquique, eran más ricas que las de Porco en Charcas. Por otro lado, varias investigaciones arqueológicas demostraron que los incas trabajaron minas en la cuenca del río Loa (Berenguer et al. 2005; Castro et al. 2004). A fin de conseguir los ricos recursos del norte chileno (minerales, guano, pescados, coca, ají, maíz) los grupos prehispánicos desarrollaron desde épocas remotas varias rutas y circuitos: norte-sur (modelo propuesto por Rostworowski en 1977), oeste-este (control de los recursos de varios pisos ecológicos según Murra en 1972) y la movilidad giratoria que combina los dos modelos anteriores (Núñez y Dillehay 1995). 


\section{Las Investigaciones de las Vías Prehispánicas del Norte Chileno}

Pocos estudios sistemáticos se han llevado a cabo sobre el tema de los caminos prehispánicos entre la frontera Perú-Chile y el $20^{\circ}$ de latitud sur. Santoro (1983), Dauelsberg (1983) así como Muñoz y Briones (1998) mencionan la presencia de una ruta con algunos tramos empedrados y muros laterales en la cordillera al este de Arica. Ubicado a más de $3.000 \mathrm{msm}$, este eje de comunicación se dirige del norte hacia el sur y corre paralelamente a la vía desértica Tacna-Tarapacá que no ha sido identificada todavía. Varios ramales este-oeste salen de esta ruta longitudinal y bajan hacia la costa. Núñez (1976), Briones y Chacama (1987), Briones et al. (1999, 2005), Sepúlveda et al. (2005), Muñoz y Chacama (2006) y Uribe (2006) enfocaron sus estudios sobre varios tipos de sitios arqueológicos (geoglifos, pinturas rupestres, petroglifos, apachetas, hábitats) asociados a las vías en el desierto al norte del río Loa. Berenguer y Cáceres (2008:138) sugieren la existencia de una ruta transversal conectando Bolivia con el valle de Tarapacá pasando por Cancosa y Lirima. En el valle de Collacagua una vía longitudinal permitía conectar la zona del salar de Huasco con Lirima. Las investigaciones de Núñez (1976) y Núñez y Dillehay (1995) se llevaron a cabo a propósito de las rutas que permitían conectar los valles-oasis así como el altiplano con la costa a fin de conseguir productos agrícolas, minerales y piedras preciosas. Muñoz y Briones (1998:59) mencionan una ruta altiplánica norte-sur todavía no estudiada que se dirige de Timalchaca hacia el salar de Surire e Isluga. Por su lado, Stehberg (2001:97) indica que la mayoría de las vías que conectan la cordillera con las tierras bajas no han sido investigadas.

\section{Las vías prehispánicas del norte chileno men- cionadas en los textos coloniales}

Numerosas crónicas indican que la red vial inca tenía dos ejes principales de comunicación paralelos: el de la cordillera de los Andes (desde la parte septentrional de Ecuador hasta el noroeste argentino) y el de la costa desértica llamado también "camino de los llanos" (Betanzos 1999 [1551]; Cieza de León 1996 [1553]; Cobo 1964 [1653]; Garcilaso de la Vega 1959 [1609]; Lizárraga 1987 [1607]). Cada vía tenía una longitud de más de
$4.000 \mathrm{~km}$. La segunda permitía conectar toda la costa, desde Tumbes, al norte del Perú, hasta la zona de Santiago de Chile. Los españoles indican que esta ruta estaba delimitada por muros de adobe o árboles en las quebradas-oasis y palos hincados en el suelo en algunas partes del desierto (Cobo 1964 [1653]II:127; Lizárraga 1987 [1607]:73-74; Sarmiento de Gamboa 2001 [1572]:120).

En cuanto al norte chileno, los documentos coloniales precisan que esta vía pasaba por los valles y lugares siguientes: Tacana [Tacna en Perú], Tarapacá, Pica, Guatacondor, Atacama [muy posiblemente San Pedro de Atacama] y Copayapo [Copiapó]. Este itinerario fue recorrido por Almagro y Valdivia a fin de conquistar el territorio chileno (Fernández de Oviedo 1959 [1550]:145-150; Lizárraga 1987 [1607]:148; Vivar 2001 [1558]:48-56). Sin embargo, desconocemos el itinerario exacto de la vía entre Tacna y Tarapacá. Asimismo, no se sabe por dónde pasaba la ruta entre Guatacondor y Atacama. Según Lizárraga (1987 [1607]:149,438-439), existía otra vía paralela al "camino de los llanos" corriendo a lo largo del océano Pacífico y ubicada a tres, cuatro, seis leguas o más del mar. En su Diccionario Jeográfico de Chile, Riso Patrón (1924:423) menciona efectivamente un tramo de "camino inca" cerca del mar, desde el río Loa hasta la quebrada Camarones. Lizárraga afirma que dos vías salían de Coquimbo para llegar a Santiago: la primera seguía la costa Pacífica y la segunda subía en dirección a la cordillera. Si estos datos son fidedignos, eso significa que existían dos rutas desde el norte chileno hasta la región de Santiago: una cerca del mar y otra más al interior del territorio pasando por Tarapacá, San Pedro de Atacama y Copiapó.

\section{Metodología}

Siguiendo la metodología de Hyslop (1976, 1984) y Beck (1979) sobre el tema de las vías prehispánicas, se necesitó primero analizar los documentos coloniales y revisar las investigaciones ya realizadas. El estudio complementario de los mapas actuales y antiguos fue indispensable a fin de realizar un análisis toponímico e identificar posibles sitios arqueológicos. El uso de las fotos aéreas y de las imágenes satelitales de Google Earth fue también importante a fin de ubicar las vías y los asentamientos prehispánicos. Después de esta primera etapa, realicé una serie de prospecciones para confirmar o infirmar los datos proporcionados 
por la documentación colonial y los mapas. Mi primera salida al campo contó con el apoyo de los profesores I. Muñoz y J. Chacama. Las prospecciones ulteriores de las vías han sido realizadas a pie con guías locales y animales de carga. Las características de las vías y de los sitios encontrados en el campo fueron registradas con fichas apropiadas. Finalmente, el uso del GPS (Global Positionning System) permitió registrar las coordenadas de los caminos y de los asentamientos prehispánicos y elaborar posteriormente mapas con el SIG (Sistema de Información Geográfica) ArcGis.

\section{Las Características Técnicas de las Vías}

El conjunto de caminos que estudiamos en el campo y que analizaremos más adelante son los siguientes: la vía longitudinal norte-sur PutreSocoroma-Zapahuira-Tignamar $(70 \mathrm{~km})$ ubicada entre 3.000 y $3.600 \mathrm{msm}$, la vía transversal esteoeste Belén-Ausipar $(50 \mathrm{~km})$ ubicada entre 3.300 y $1.200 \mathrm{msm}$ y la vía transversal este-oeste Ancuaque (zona de Cariquima)-cabeceras de la quebrada de Tarapacá ( $24 \mathrm{~km}$ ) ubicada entre 4.000 y $4.500 \mathrm{msm}$ (Figura 1).

Cualquiera que sea la topografía, el tipo de camino más frecuente no tiene pavimento: la vía fue despejada de las piedras más grandes y sus dos lados han sido delimitados por una concentración mayor de piedras y/o de vegetación. A veces, como es el caso a la entrada norte de Zapahuira o al norte de Belén, los bordes de la vía están conformados por piedras alineadas cuyas dimensiones no sobrepasan los $50 \mathrm{~cm}$ por $30 \mathrm{~cm}$. Existen pocos tramos de vías pavimentadas entre Putre y Tignamar. La sección empedrada más larga se encuentra al sur de Socoroma. Mide menos de $2 \mathrm{~km}$ con un ancho de 3-5 m y está conformada en algunos segmentos por un pequeño muro de contención que alcanza raramente $50 \mathrm{~cm}$ de altura. En la parte final del tramo, cortado por la carretera asfaltada, piedras grandes (más de $50 \mathrm{~cm}$ x $50 \mathrm{~cm}$ x $50 \mathrm{~cm}$ ) ubicadas en cada lado delimitan la vía. Las piedras del pavimento del camino son de formas irregulares y miden menos de $50 \mathrm{~cm}$ por $30 \mathrm{~cm}$. De vez en cuando se encuentran piedras de dimensiones mayores, a menudo desbastadas y de formas aproximadamente rectangulares. Fueron utilizadas especialmente como escaleras, para edificar el muro de contención o drenar las aguas.

A la entrada norte de los pueblos de Socoroma, Chapiquiña y Belén se nota la presencia de cortos tramos empedrados (250 m, $400 \mathrm{~m}$ y $200 \mathrm{~m}$ respectivamente) con un ancho de 2-3 $\mathrm{m}$ y muros laterales sin mortero que alcazan 1-1,5 m de altura. Presentan

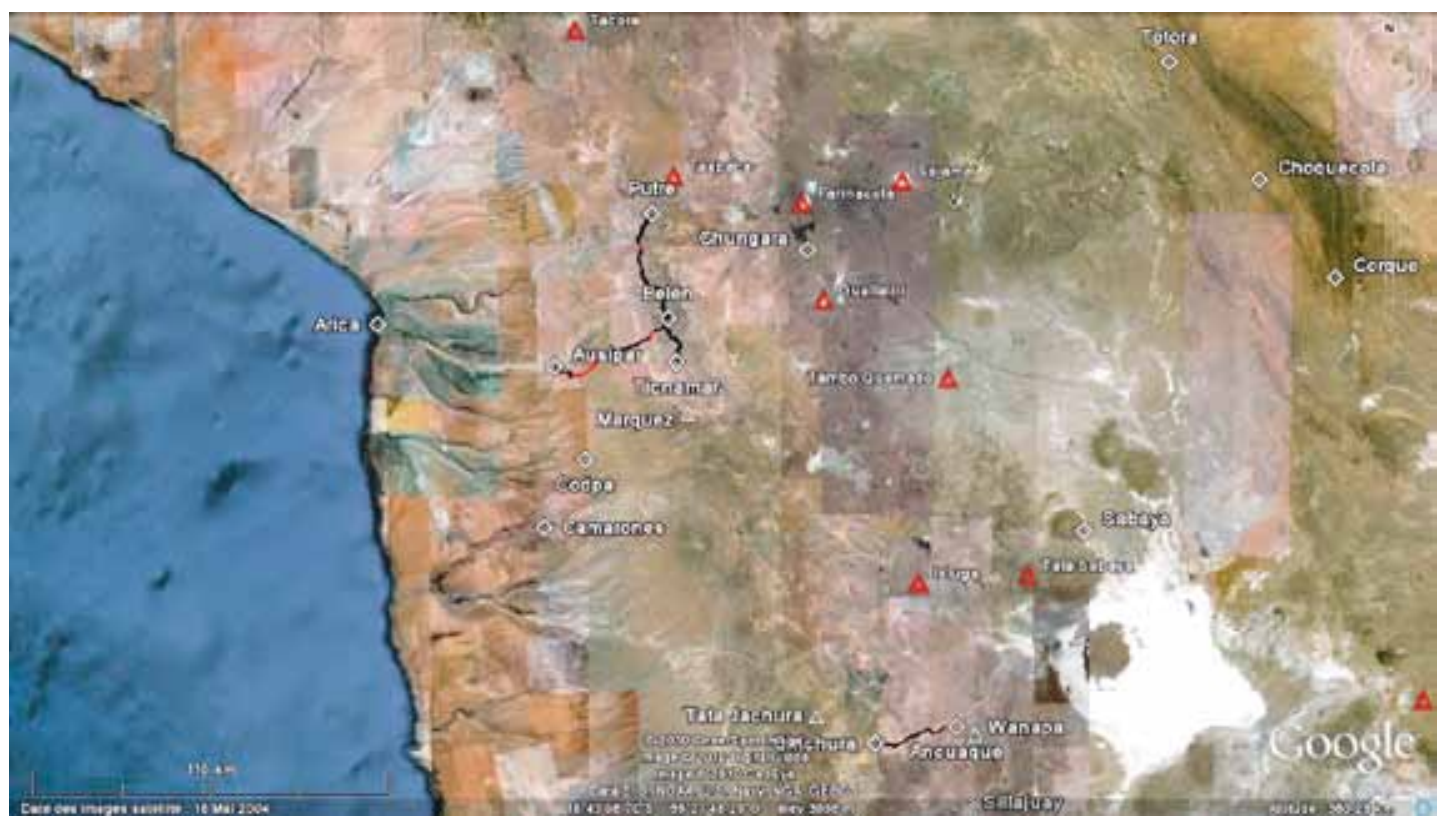

Figura 1. Vías prehispánicas estudiadas (los tramos rojos presentan elementos de construcción).

Prehispanic roads survey (the red segments have been constructed). 
las mismas características que la sección pavimentada cerca de Socoroma: piedras de dimensiones medianas $\mathrm{y}$ de formas irregulares para el pavimento y piedras mayores y de formas paralelepípedas para las escaleras y drenar las aguas. Sin embargo, dudamos del origen prehispánico de estos pavimentos porque están asociados a dichos tres pueblos que fueron fundados después de la conquista española. Efectivamente, el plano en damero de estos pueblos y su ubicación en terreno llano o en fondo de quebrada es característico de los pueblos construidos en la época colonial (Matienzo 1967 [1567]:48-50) y republicana. Además, cabe señalar que estos tramos pavimentados con muros laterales no están asociados a asentamientos prehispánicos. Los sitios de Laco Alto, Laco Bajo y Cayllama se encuentran a más de $4 \mathrm{~km}$ (o sea más de una hora de caminata) de Chapiquiña, mientras que los sitios de Ancopachane, Chajpa, Incahullo y Huaihuarani están ubicados a más de $1 \mathrm{~km}$ al oeste de Belén. Al norte de este pueblo, la vía que viene de Pachama se bifurca: un camino prehispánico se dirige hacia los cuatro sitios arqueológicos mencionados y el otro, posiblemente de origen colonial, conduce a Belén. En algunas pendientes, las vías tienen un muro de contención con piedras de formas irregulares sin mortero. En general dicho muro mide menos de $1 \mathrm{~m}$ de altura. Sin embargo, entre Pachama y Belén, en una pendiente fuerte existe un corto tramo con un muro de contención que alcanza casi $2 \mathrm{~m}$ de altura.

Entre Belén y Ausipar se encuentra uno de los tramos más largos del norte chileno con evidencias constructivas (muro de contención, pavimento). Este tramo de $10 \mathrm{~km}$ se encuentra en la ladera oeste de la sierra de Huaylillas y baja hacia el mar bordeando la ladera sur del valle de Azapa. Las secciones con muro de contención y pavimento en las laderas (Figura 2) alternan con las secciones despejadas y bordeadas con piedras en los lados en terreno llano (Figura 3 ). El ancho de la vía oscila entre 1,5 y $2,5 \mathrm{~m}$ en las laderas mientras que en terreno llano su ancho varía de 4 hasta $7 \mathrm{~m}$. En las laderas el camino tiene un muro de contención sin mortero cuya altura puede alcanzar

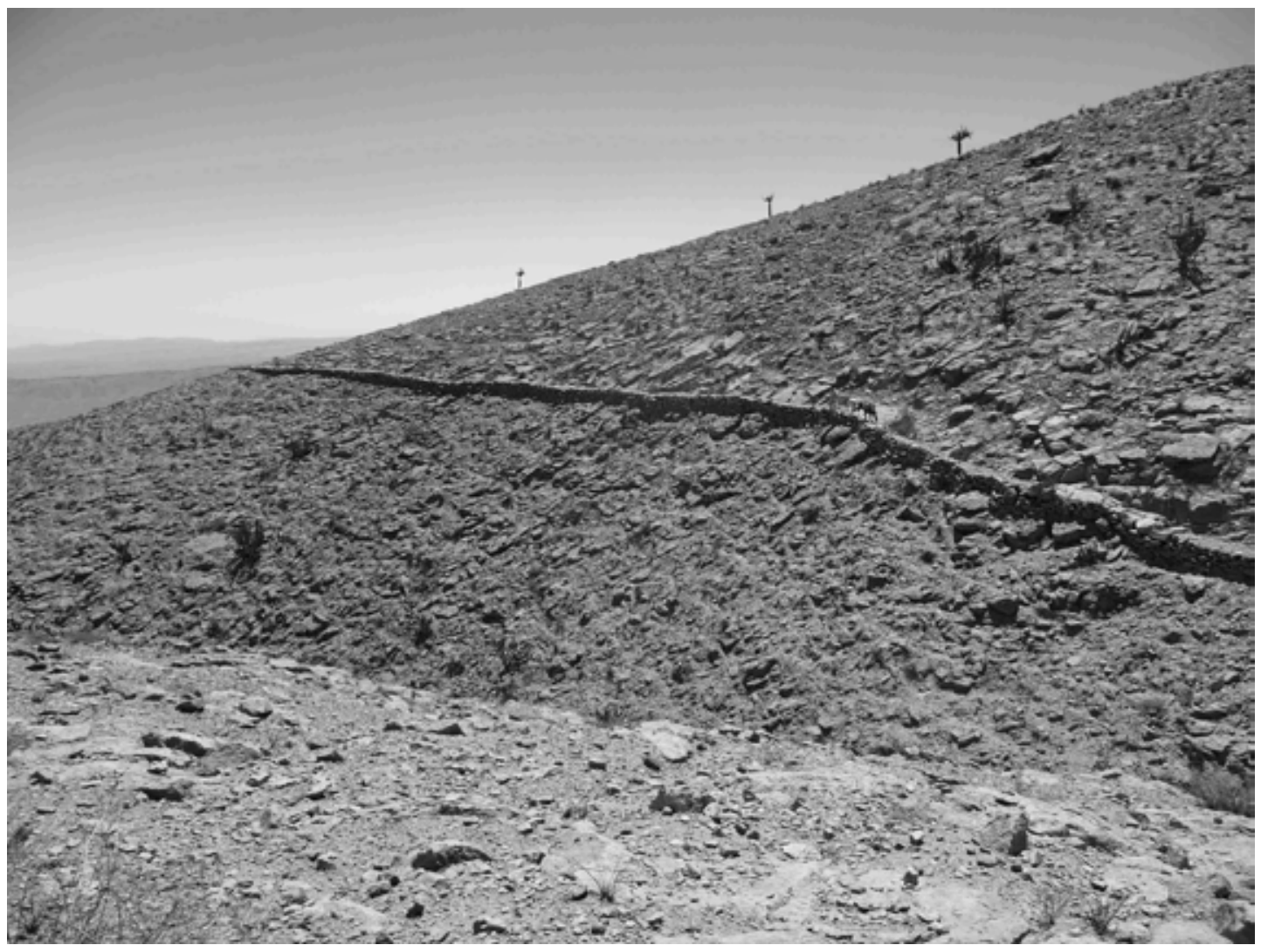

Figura 2. Tramo de la vía Belén-Ausipar con un muro de contención. Section of the Belén-Ausipar road with a retention wall. 


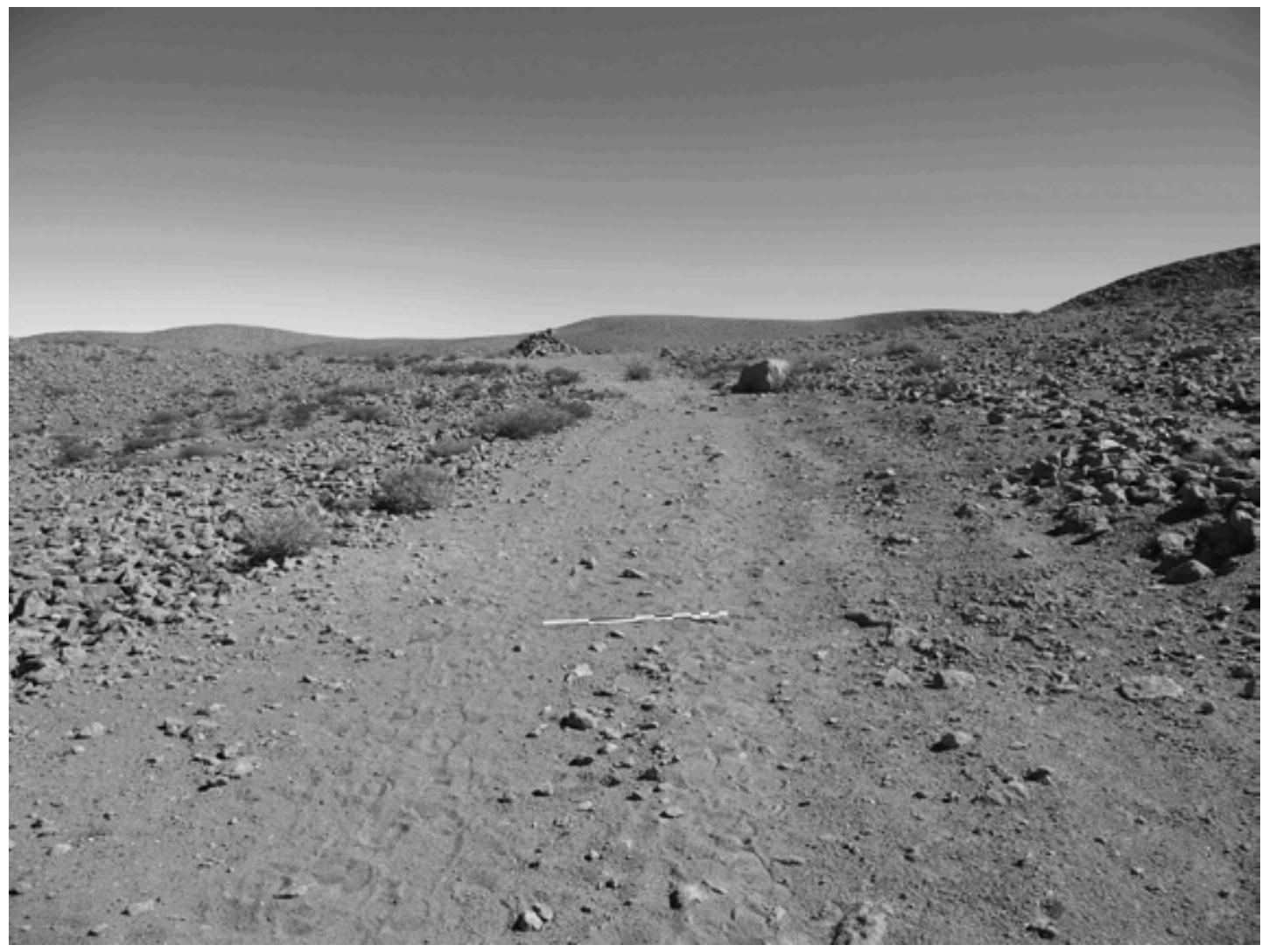

Figura 3. Tramo despejado de la vía Belén-Ausipar.

Cleared segment of the Belén-Ausipar road.

$2 \mathrm{~m}$. Las piedras del muro son de formas irregulares y miden hasta $70 \mathrm{~cm}$ de largo por $40 \mathrm{~cm}$ de ancho. Estos elementos indican que la construcción de este tramo de $10 \mathrm{~km}$ implicó un trabajo importante por parte de las poblaciones locales.

Entre la zona de Cariquima y las cabeceras de la quebrada Tarapacá (Chichura) existe una corta sección -menos de $1 \mathrm{~km}$ - de vía empedrada al oeste de Ancuaque. Ubicada a casi $4.000 \mathrm{msm}$, fue construida en una ladera y tiene un muro de contención sin mortero cuya altura no alcanza $1 \mathrm{~m}$. Su ancho es de 1,5-2 $\mathrm{m}$ y su pavimento ha sido en gran parte destruido por los équidos. A veces, el lado de la vía opuesto al muro de contención está conformado por piedras alineadas. Los muros de contención encontrados no son muy altos porque las pendientes son poco abruptas y el clima árido del norte chileno explica la poca presencia de sistemas de drenaje asociados a las vías. Teniendo en cuenta la destrucción posible de varios tramos empedrados desde la conquista española, podemos constatar que quedan hoy día muy pocas secciones de caminos construidos en el norte chileno: 10,62\% de las vías recorridas, o sea $15,3 \mathrm{~km}$ sobre $144 \mathrm{~km}$.

\section{Los Sitios Arqueológicos Asociados a las Vías}

Varios tipos de sitios arqueológicos están asociados a la vía prehispánica Putre-Tignamar. La mayoría de ellos presentan un patrón de asentamiento del período Intermedio Tardío caracterizado por recintos de planta circular u oval construidos en la cima o las laderas de los cerros (Muñoz y Chacama 2006:44-50). La presencia inca en la cordillera al este de Arica es notable especialmente en los sitios de Zapahuira, Laco Alto e Incahullo y se señala por la presencia de estructuras típicamente incas con planta rectangular y vanos trapezoidales organizadas alrededor de espacios abiertos (Dauelsberg 1983:67-73; Muñoz y Chacama 2006:214-216,246). El culto de los muertos en los sitios asociados a la vía Putre-Tignamar (Zapahuira, Caillama, Huaihuarani, 
Incahullo, Lupica, Saxamar) se expresa, entre otros, a través de las sepulturas: torres funerarias llamadas comúnmente chullpas $^{1}$, cistas y aleros sellados con muros (Dauelsberg 1983:73; Romero 2003; Muñoz 2005a:342-343; 2007:261; Muñoz y Chacama 2006:85; Horta 2010) (cf. el artículo de Duchesne y Chacama en este número).

\section{El Culto a los Volcanes y a los Cerros-Nevados}

Albornoz (Duviols 1967:20-21), uno de los más famosos extirpadores de idolatrías, indica que los incas habían instalado mitmaqkuna ${ }^{2}$ al pie de los "cerros de nieve y bolcanes que miran hacia el mar" desde el volcán Sarasara (al oeste de Arequipa) hasta la altura del río Loa en Chile. El eclesiástico precisa que dichos volcanes y cerros nevados eran "guacas pacarisca", razón por la cual los incas establecieron dichos mitmaqkuna con camélidos a fin de servir a estas entidades sagradas ligadas a las fuerzas telúricas y celestes, la fertilidad y los muertos (Bouysse-Cassagne y Bouysse 1984; Bouysse-Cassagne 1988). Albornoz señala que estos mitmaqkuna eran oriundos del Chinchaysuyu (la parte norte del Tawantinsuyu) sin más precisiones. Sabiendo que los incas mudaban a la gente acostumbrada a vivir en pisos ecológicos similares, Bouysse-Cassagne y Bouysse (1984:60-61) sugieren que dichos mitmaqkuna provenían posiblemente de Ecuador -o sea del Chinchaysuyu-donde existen también volcanes. En cuanto a dichos mitmaqkuna $\mathrm{y}$ a las poblaciones locales viviendo en la proximidad de los volcanes, Albornoz escribe lo siguiente: "estas nasciones que mudava de una parte a otra que llamava mitimas en forma que sirviesen a las guacas dichas pacaricas que el [inca] reedificava y a estos mitimas ponía un caudillo superintendente que llamava tocricoc ${ }^{4}$ para su govierno de los mitimas o de los naturales para que les diese aviso y sustentase a quietud la tal provincia" (Duviols 1967:21). Si las informaciones mencionadas por Albornoz son fidedignas eso significa que el "mapa étnico" del territorio norte chileno y sur peruano era sumamente complejo: una franja de mitmaqkuna cerca de los volcanes; al este de dicha franja los grupos collas, lupacas, pacajes y carangas viviendo en el altiplano (Bouysse-Cassagne 1978); al oeste de la susodicha franja las colonias de los grupos altiplánicos y las poblaciones nativas de la costa desértica (Durston e Hidalgo 1997; Hidalgo y Focacci 1986; Rivière 1982:21-22). Bouysse-Cassagne y
Bouysse (1984:61-62) sugieren que los incas no habrían instalado mitmaqkuna en la zona de los volcanes y de los nevados de la cordillera occidental únicamente con fines religiosos, sino también para controlar los movimientos de los grupos altiplánicos y de sus colonias costeras y dejar su huella en este espacio sagrado. Hasta el día de hoy, los pueblos de mitmaqkuna instalados por los incas próximos a los volcanes chilenos y bolivianos no han sido identificados. En el Perú, Ziólkowski (2008) encontró varios pueblos en la zona del volcán Coropuna. Se encuentran entre 3.000 y $3.800 \mathrm{msm}$ donde se practica la agricultura. Estos sitios cuentan hasta varias decenas de estructuras de planta rectangular con plazas y plataformas ceremoniales. $\mathrm{Al}$ contrario de los volcanes peruanos, los de Chile y Bolivia dominan una meseta ubicada entre $4.000 \mathrm{y}$ $4.500 \mathrm{msm}$ donde la agricultura se limita al cultivo de la quinoa. Eso significa que los mitmaqkuna practicaban más que todo la crianza de camélidos. Se necesita seguir investigaciones en archivos y realizar prospecciones sistemáticas para ubicar y registrar los asentamientos de los mitmaqkuna.

A un kilómetro al sur del lago Chungara, a más de $4.500 \mathrm{msm}$, existe un sitio arqueológico éponimo conformado por una decena de estructuras de planta rectangular y una plataforma ${ }^{5}$ con piedras canteadas. La mampostería fina de dicha plataforma hace de este edificio uno de los más singulares del norte chileno (Aldunate 2001:50; Chacón y Orellana 1982). Este pequeño asentamiento inca tenía muy posiblemente una función eminentemente religiosa. La arquitectura de la plataforma lo atestigua. Efectivamente, cabe recordar que los edificios incas construidos con una mampostería muy fina tenían una función eminentemente ceremonial (cf. los templos del Sol de Cusco y de Vitcos, Sacsayhuaman, el santuario de Pacaritambo). Más que todo, desde la plataforma de Chungara se puede admirar los volcanes-mallku Sajama, Parinacota, Pomerape y Guallatiri así como los nevados Acotango y Capurata. En efecto, Chungara está rodeado al norte, al este y al sur por dichos volcanes y nevados sagrados.

En la cordillera ubicada al este de Arica, durante el recorrido a lo largo del camino prehispánico entre Putre y Zapahuira, pude constatar que los peatones pueden admirar especialmente en varios portezuelos y líneas de crestas -donde se encuentran apachetas asociados a cerámica prehispánica y calvarios recientes- el volcán Tarapacá. En la cumbre de este volcán, Reinhard (2002:85-89) encontró una figurina 
inca tallada en una concha de mullu (Spondylus sp.) que atestigua obviamente la importancia del culto volcánico de este mallku. Al sur de Zapahuira se pierde de vista el Tarapacá.

Entre Ancuaque (al oeste de Cariquima) y las cabeceras de quebrada de Tarapacá hemos estudiado un tramo de vía prehispánica de $24 \mathrm{~km}$ que permite conectar el altiplano boliviano (zona de Sabaya, salar de Coipasa) con la quebrada de Tarapacá y la costa chilena. Durante el recorrido realizado de este a oeste, el cerro de mayor importancia que los caminantes pueden ver es el Cariquima (5.365 msm) ubicado a más de $40 \mathrm{~km}$ al sur del volcán Tata Sabaya. Poco tiempo antes de llegar al portezuelo Alto Quiñuta $(4.486 \mathrm{msm})$, el Cariquima (llamado también Mama Wanapa) desaparece de la vista de los caminantes. En el portezuelo, donde se encuentran dos apachetas de 1-1,5 m de altura, aparece el Tata Jachura (5.252 msm) con sus dos picos que los peatones siguen viendo bajando hacia Chusmiza. Resumiendo, el Cariquima y el Tata Jachura son los dos nevados omnipresentes durante el tramo recorrido. Reinhard y Sanhueza (1981:1013, 28-30) indican que recintos prehispánicos de planta rectangular están ubicados en la cumbre de estos cerros. Sin embargo, no encontraron artefactos anteriores a la época colonial (cerámica, metal, textil), lo que si bien pone en duda la antigüedad de las construcciones identificadas no cuestiona la importancia del Cariquima y del Tata Jachura como divinidades.

A lo largo del camino Belén-Ausipar (50 km) hemos registrado 17 apacheta y 11 marka. Según la nomenclatura utilizada por los arqueólogos chilenos (Muñoz y Briones 1998:56), las marka son montículos de piedras más pequeños que los apacheta. La mayoría de los apacheta (14, un $82,35 \%)$ y marka (5, un $71,42 \%$ ) están ubicados entre 3.090 y $3.564 \mathrm{msm}$ y se encuentran entre la margen izquierda del río Ticnamar y la cresta de la sierra de Huaylillas. Desde dichos apacheta y marka se pueden ver todas las cimas de la precordillera de Arica y especialmente el volcán-nevado Tarapacá así como el cerro Marquez localizado al sur de la precordillera. Desde los apacheta más elevados -encima de 3.-400 msm- se observa además el volcán Tacora ubicado a $90 \mathrm{~km}$ al norte.

El tramo Belén-Ausipar es un eje de comunicación importante conectando la costa con la precordillera de Arica y el altiplano. Al este de Belén el camino se dirige hacia Bolivia, sigue el curso del río Lauca donde se encuentran las famosas chullpa pintadas de los carangas (Gisbert 1994) y finalmente se conecta a la vía Porco-Chucuito-Cusco a la altura del tampu de Choquecota (Vaca de Castro 1908 [1543]:438). Cabe señalar la posición relevante de las chullpas del río Lauca en la red vial regional porque este importante lugar religioso es un cruce de caminos que conecta la vía de la costa desértica y la vía serrana Porco-Cusco (Figura 4). En la parte chilena los caminos pasan por los valles de Azapa, Codpa y Camarones donde se encuentran numerosos sitios arqueológicos (Muñoz 1989; Muñoz et al. 1987; Niemeyer y Schiappacasse 1981; Santoro y Muñoz 1981; Schiappacasse y Niemeyer 1997, 2002). Por el lado boliviano los caminos salen de los antiguos tampu incas de Choquecota, Corque y Andamarca localizados a lo largo de la ruta PorcoCusco (Vaca de Castro 1908 [1543]:438).

Los apacheta constituyen elementos mediadores conectando las vías con las entidades sagradas del paisaje como los volcanes, los cerros y los nevados. Así que los caminos permiten juntar en la cosmovisión: los elementos naturales del paisaje y los ancestros encarnados por los cerros. Siguiendo esta lógica, las vías constituyen entonces caminos sagrados: caminar es desplazarse en un espacio salpicado por una multiplicidad de elementos naturales (cerros, rocas, cuevas, fuentes, lagunas, ríos) y antrópicos (santuarios, chullpa, etc.) vinculados con el culto de los antepasados y de las divinidades. Según el lugar, el calendario ritual y la importancia del ancestro o de la divinidad, el grado de sacralidad -y de las ofrendas- de los caminos podía variar. Numerosos investigadores estudiaron el tema del culto de los cerros en los Andes destacando una jerarquía de las divinidades y de los ancestros desde la época prehispánica hasta el día de hoy (Bellenger 2005; Cruz 2009; Duviols 1966; Favre 1967; Leoni 2005; Martínez 1976, 1983; Platt et al. 2006; Zuidema 1973). Los lugares donde aparecen y se pierden de vista los volcanes y cerros sagrados y donde se encuentran los apacheta constituían posiblemente los límites del territorio o jurisdicciones de estos mallku.

\section{Patrón de Asentamiento y Pacarina}

El estudio del patrón de asentamiento de los pueblos asociados a los caminos es necesario para entender las funciones múltiples de las vías y el significado profundo de los sitios de hábitat en el paisaje sagrado. Al momento de la conquista los 


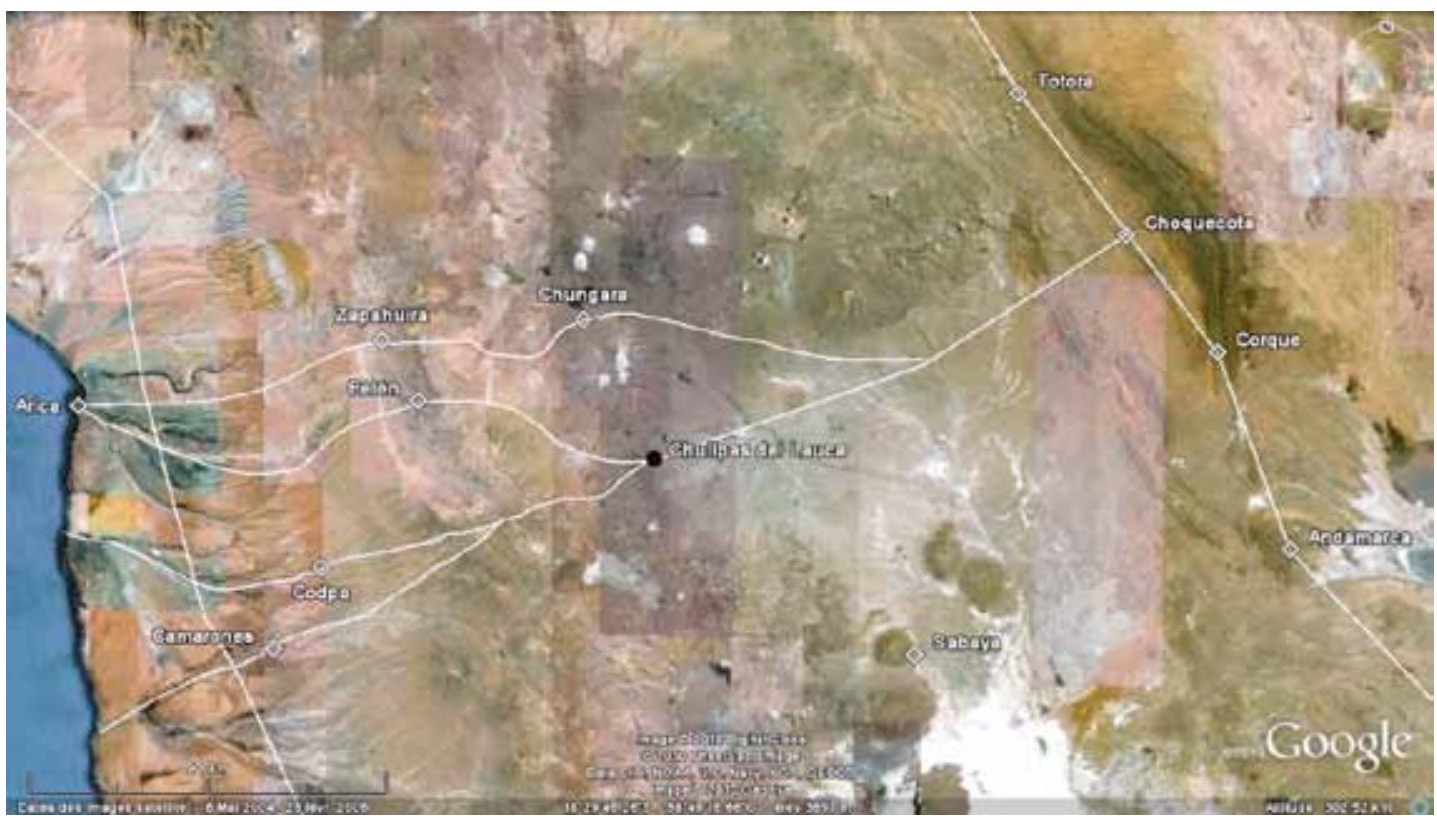

Figura 4. Las chullpas del Lauca y la red vial prehispánica regional.

The chullpas of the Lauca and the prehispanic regional road system.

españoles se dieron cuenta que muchos pueblos andinos asociados a las vías eran edificados en lugares altos y de difícil acceso: en las líneas de cresta y la cumbre de los cerros. Algunos de ellos estaban cercados por muros (Cieza de León 1996 [1553]:130; Cobo 1964 [1653]II:240). Por falta de conocimientos de los usos y costumbres de las poblaciones locales los españoles calificaron a estos asentamientos como pueblos fortificados o fortalezas y desde la época colonial el significado de la palabra pucara es el de "fortaleza o castillo" (Bertonio 1612:275; González Holguín 1608:295;). Como se sabe, el sentido original de numerosas palabras quechuas y aymaras fue modificado por los conquistadores para traducir los conceptos cristianos y por desconocimiento de las creencias de las comunidades andinas ${ }^{6}$. El término pucara forma parte de estas palabras cuyo sentido pudo cambiar con la llegada de los españoles. En efecto, en su famoso Lexicón el dominico Santo Tomás (1951 [1560]:173,341) nos da posiblemente el sentido original del término pucara: "barrera de muro o muro; muro de ciudad". Se trata probablemente de los muros que cercaban algunos pueblos ubicados en los cerros.

El patrón de asentamiento dominante del Período Intermedio Tardío en toda el área andina está caracterizado por la existencia de sitios con recintos de planta circular u oval edificados en lugares altos: cimas o laderas de cerros, líneas de crestas (Arkush 2005; Bonavia 1968; Bonnier y Rozenberg 1982; Covey 2003; D'Altroy y Hastorf 2001; González Carré et al. 1987; Lavallée y Julien 1973; Lecoq 1999; Michel 2000; Muñoz y Chacama 2006; Nielsen 2000; Schjellerup 2005). Dichos sitios reciben el calificativo de defensivo o fortificado en numerosas publicaciones científicas y de hecho algunos de ellos están rodeados de muros. Esta situación defensiva generalizada habría sido la consecuencia de tensiones entre las comunidades después de la caída de las civilizaciones huari y tiahuanaco. Esta interpretación está apoyada por varias crónicas coloniales mencionando un período de conflictos y "behetrías" antes de las conquistas incas (Cobo 1964 [1653]II:58; Guaman Poma de Ayala 1936 [1613]:63-64; Murúa 1987 [1611]:47;). Sin embargo, se necesita leer y utilizar la documentación colonial con mucho cuidado. Cabe recordar que la mayoría de los informadores de los cronistas eran miembros de la élite inca cusqueña. Podemos imaginar que los incas quisieron mostrar a los europeos que sus antepasados conquistaron los Andes a fin de civilizar a los grupos no-incas viviendo en una supuesta behetría. Este discurso 
de los incas civilizados y civilizadores parece bastante obvio y conviene matizar esta época de "behetrías, desorden y guerras" sin negar posibles tensiones entre las comunidades y dentro de ellas. Además, cabe señalar la dificultad para comprobar arqueológicamente guerras y conflictos en los Andes mediante una metodología adaptada y pertinente (Arkush y Stanish 2005; Topic y Topic 1997; Torres-Rouff et al. 2005).

Fuera del factor defensivo otras razones pudieron motivar a las poblaciones andinas para edificar sus pueblos en lugares altos y no en el fondo de los valles: reducir las consecuencias destructivas de derrumbes, deslizamientos y aluviones (Muñoz 2005b:117); aprovechar al máximo las tierras agrícolas más productivas ubicadas en el fondo de los valles; aprovechar el máximo de la insolación diurna (las piedras de las casas restituyen en la noche fría el calor acumulado a lo largo del día).

Por otro lado existe un argumento muy relevante, de orden simbólico y religioso, para explicar la presencia de numerosos pueblos en lugares altos. Si muchos españoles no supieron entender los usos $\mathrm{y}$ costumbres de las poblaciones nativas, otros y especialmente los eclesiásticos hicieron este esfuerzo para destruir estas mismas costumbres. El jesuita Arriaga (1999 [1621]:30), gran conocedor de las creencias de las poblaciones andinas que escribió un manual para extirpadores de idolatrías, explica lo siguiente

\section{Y ésta [la pacarina] es una de las causas por que rehusan tanto la reducción de sus pueblos y gustan de vivir en unos sitios tan malos y trabajosos que algunos he visto que era menester bajar por el agua cerca de una legua y a muchos no se puede bajar ni subir si no es a pie y la principal razón que dan es que está allí su pacarina.}

Así, según el jesuita la gente se estableció en sectores de difícil acceso para vivir en el lugar mismo de su pacarina, aun si se necesitaba caminar mucho para abastecerse de agua. Las investigaciones de Arkush (2005:266-267) en el territorio colla subrayan efectivamente el problema de acceso al agua en la mayoría de los sitios del Intermedio Tardío ubicados en los cerros y la imposibilidad de resistir un cerco prolongado.

Según Arriaga ni la cercanía al agua ni el carácter defensivo del lugar motivaron la ubicación de los pueblos sino más bien la localización del lugar de origen mítico, o pacarina de un grupo, que traduce al más alto nivel el culto de los muertos y de los antepasados.

Los incas, mediante la institución de los mitmaqkuna, mudaban la gente de un pueblo a otro, pero como lo nota Albornoz (Duviols 1967:21), al mudarse estos se trasladaban siempre con una reliquia de su pacarina original: agua de una fuente, pedazo de tierra o de roca. Llegados a su nuevo pueblo los mitmaqkuna se apropiaban del nuevo territorio poniendo los nombres de la pacarina, cerros y ríos del territorio oriundo (Bouysse-Cassagne y Bouysse 1984:61-62).

Los eclesiásticos se percataron del vínculo estrecho entre la ubicación del pueblo, las tierras de la comunidad y el culto de los antepasados. La mejor manera de luchar contra estas prácticas "idólatras" era mudar a la gente de su pueblo, cortar las personas de sus raíces y eso es una de las principales razones de la creación de los pueblos de reducción ${ }^{7}$ (Platt et al. 2006:516; Toledo 1986:281-282).

\section{Conclusión}

Aunque el norte chileno sea muy árido, hostil a la instalación humana y poco poblado, los incas tuvieron intereses muy importantes en esta región atravesada por el famoso "camino de los llanos" que corre a lo largo de toda la costa pacífica. Varias vías conectando las tierras bajas con el altiplano permitían el transporte de los productos costeros: recursos marinos, guano, maíz, coca, ají, etc. Las famosas minas de Tarapacá (i.e Huantajaya cerca de Iquique), cuya plata era más pura que la de Porco (Cobo 1964 [1653]II:131), tenían un valor simbólico de suma importancia para los incas porque una parte de los objetos metálicos eran ofrecidos a los muertos en el marco de ritos ligados a la fertilidad.

Las características técnicas de las vías prehispánicas constituyen respuestas y adaptaciones al medio ambiente y a la topografía: muros de contención en las laderas cuya altura varía con el grado de la pendiente, desarrollo de un sistema de drenaje en relación con la pluviometría local. En el norte chileno existen hoy día pocos tramos de caminos (15,3 km, un 10,62\% de los $144 \mathrm{~km}$ estudiados) con evidencias constructivas (pavimento, muro de contención).

Desde la zona de Arequipa hasta el río Loa (Chile), los incas instalaron con fines religiosos 
mitmaqkuna en la zona de los volcanes y nevados de la cordillera occidental de los Andes. Efectivamente, los incas pensaban que estas entidades eran huaca y pacarisca (Duviols 1967:20-21), es decir, lugares, sagrados vinculados con los muertos y los orígenes míticos de las poblaciones andinas.

Los apacheta y marka ubicados a lo largo de las vías constituyen mediadores entre los caminos y los elementos sagrados del paisaje como los cerros, volcanes, rocas... que representaban a menudo antepasados -reales o míticos-petrificados. Las vías no sólo conectan lugares sino también permiten la articulación entre el caminante y el paisaje salpicado de elementos vinculados con los ancestros y el pasado. Caminar es desplazarse en el espacio y viajar en el tiempo.

Desde hace cuarenta años, las investigaciones científicas han demostrado que el patrón de asentamiento de los sitios del período Intermedio Tardío dominante en el área andina está caracterizado por la presencia de estructuras de planta oval o circular aglutinadas en la cima o las laderas de los cerros. Basándonos en el estudio crítico de los textos coloniales y sin refutar probables funciones defensivas sugerimos que dicho patrón de asentamiento refleja también preocupaciones ligadas al culto de los antepasados y especialmente a la pacarina como lugar de origen mítico de cada comunidad. Establecer su pueblo en el lugar mismo de su pacarina traduce el vínculo muy estrecho entre los seres vivos y sus antepasados ligados a la posesión del territorio y la fertilidad.

Agradecimientos: Este estudio fue realizado gracias a una beca postdoctoral del comité Ecos-Sud (Francia) en el marco del Proyecto Ecos-Conicyt C06H04 «Dinámicas culturales en los Andes del Centro-Sur». Agradecemos especialmente a los arqueólogos de la Universidad de Tarapacá de Arica por su apoyo, su gentileza y las discusiones estimulantes: Iván Muñoz, Juan Chacama, Calogero Santoro, Luis Briones y Marcela Sepúlveda. Debemos agradecer con mucho cariño al personal del Museo y de la Biblioteca de Azapa: Teresa Cañipa, Jorge Andrade, Jenny Pérez, Celedonio Tomás y Víctor Balbontín. Agradecemos también a los evaluadores por sus sugerencias y sus comentarios. Por fin tenemos que dar las gracias a Thérèse Bouysse-Cassagne por sus consejos y su propuesta de participar en dicho Proyecto Ecos-Conicyt.

\section{Referencias Citadas}

Aldunate, C. 2001. Arquitectura y poder. En Tras la Huella del Inka en Chile, editado por C. Aldunate y L. Cornejo, pp. 45-52. Museo Chileno de Arte Precolombino, Santiago.

Anónimo 1906. Discurso de la sucesión y gobierno de los Yngas. En Juicio de Límites entre el Perú y Bolivia, editado por V. Maurtua, pp. 149-165. Imprenta de Henrich y Comp., Barcelona.

Arkush, E. 2005. Colla Fortified Sites: Warfare and Regional Power in Late Prehispanic Titicaca Basin, Peru. Ph.D. Dissertation, University of California, Los Angeles.

Arkush, E. y C. Stanish 2005. Interpreting conflict in the Ancient Andes. Implications for the archaeology of warfare. Current Anthropology 46:3-28.

Arriaga, J. 1999 [1621]. La Extirpación de la Idolatría en el Pirú. Editado por H. Urbano. Centro de Estudios Regionales Andinos Bartolomé de Las Casas, Cusco.

Bandera, D. 1920 [1557]. Relación del Origen e Gobierno que los Ingas Tuvieron. Colección de Libros y Documentos referentes a la Historia del Perú, Tomo III, Horacio Urteaga, Lima.

Beck, C. 1979. Ancient Roads on the North Coast of Peru. Ph.D. Dissertation, University of California, Berkeley.

Bellenger, X. 2005. El gran pago de Mulsina o el arte de mover las montañas. Bulletin de l'Institut Français d'Etudes Andines 34:235-249.
Berenguer, J. 2000. Tiwanaku. Señores del Lago Sagrado. Museo Chileno de Arte Precolombino, Santiago.

Berenguer, J. e I. Cáceres 2008. Los inkas en el altiplano sur de Tarapacá: el Tojo revisitado. Chungara Revista de Antropología Chilena 40:121-143.

Berenguer, J., I. Cáceres, C. Sanhueza y P. Hernández 2005. El Qhapaqnan en el alto Loa, norte de Chile: un estudio micro y macromorfológico. Estudios atacameños 29:7-39.

Berthelot, J. 1977. Une Région Minière des Andes Péruviennes: Carabaya Inca et Espagnole (1460-1630). Tesis de doctorado. Ecole des Hautes Etudes en Sciences Sociales, Université Paris X-Nanterre, Paris.

Bertonio, L. 1612. Vocabulario de la Lengua Aymara. Editado por F. del Canto, Juli.

Betanzos, J. 1999 [1551]. Suma y Narración de los Incas. Editado por María del Carmen Martín Rubio. Universidad Nacional de San Antonio Abad del Cusco, Cusco.

Bonavia, D. 1968. Investigaciones arqueológicas en el Mantaro Medio. Revista del Museo Nacional 35:211-294.

Bonnier, E. y C. Rozenberg 1982. L'Occupation Humaine dans le Bassin du Shaka-Palcamayo à l'Intermédiaire Récent (Andes Centrales du Pérou). Tesis de doctorado, Ecole des Hautes Etudes en Sciences Sociales, Paris. 
Bouysse-Cassagne, T. 1978. L'espace aymara: urco et uma. Annales ESC 5-6:1057-1080.

- - - 1988. Lluvias y Cenizas, dos Pachacuti en la Historia. Con la colaboración de P. Bouysse. Hisbol, La Paz.

- - - 1997. Le palanquin d'argent de 1'Inca: petite enquête d'ethnohistoire à propos d'un objet absent. Technique et Culture 29:69-111.

Bouysse-Cassagne, T. y P. Bouysse 1984. Volcan indien, volcan chrétien. A propos de l'éruption du Huaynaputina en l'an 1600 (Pérou méridional). Journal de la Société des Américanistes 70:43-68.

Briones, L. y J. Chacama 1987. Arte rupestre de Ariquilda: análisis descriptivo de un sitio con geoglifos y vinculación con la prehistoria regional. Chungara 18:15-66.

Briones, L., P. Clarkson, A. Díaz y C. Mondaca 1999. Huasquiña, las chacras y los geoglifos del desierto: una aproximación al arte rupestre andino. Diálogo Andino 18:39-61.

Briones, L., L. Núñez y V. Standen 2005. Geoglifos y tráfico prehispánico de caravanas de llamas en el desierto de Atacama (Norte de Chile). Chungara Revista de Antropología Chilena 37:195-223.

Castro, V., V. Varinela, C. Aldunate y E. Araneda 2004. Principios orientadores y metodología para el estudio del Qhapaqñan en Atacama: desde el Portezuelo del Inka hasta Río Grande. Chungara Revista de Antropología Chilena 36:463-481.

Cerrón Palomino, R. 2006. Tucuyricoc. Boletín de la Academia Peruana de la Lengua 42:209-226.

Cieza de León, P. 1988 [1553]. La crónica del Perú. Biblioteca Peruana, Peisa, Lima.

- - - 1996 [1553] Crónica del Perú, segunda parte. Editado por F. Cantú. Pontificia Universidad Católica de Lima, Fondo Editorial, Lima.

Cobo, B. 1964 [1653]. Historia del Nuevo Mundo. Biblioteca de Autores Españoles, Tomos XCI-XCII, Atlas, Madrid.

Covey, R. 2003. The Vilcanota Valley (Peru): Inka State Formation and the Evolution of Imperial Strategies. Doctoral Dissertation, University of Michigan, Ann Arbor.

Cruz, P. 2009. Huacas olvidadas y cerros santos. Apuntes metodológicos sobre la cartografia sagrada en los Andes del sur de Bolivia. Estudios Atacameños 38:55-74.

Chacón, S. y M. Orellana 1982. El tambo Chungara. Actas del VIII Congreso de Arqueología Chilena, pp. 247-255. Ediciones Kultrún, Santiago.

D'Altroy, T. y C. Hastorf (eds.) 2001. Empire and Domestic Economy. Kluwer Academic Publishers, New York.

Dauelsberg, P. 1983. Investigaciones arqueológicas en la sierra de Arica, sector Belén. Chungara 11:63-83.

Diez de San Miguel, G. 1964 [1567]. Visita Hecha a la Provincia de Chucuito por Garci de San Miguel en el Año 1567. Editado por W. Espinoza Soriano. Casa de la Cultura del Perú, Lima.

Duffait, E. 2007. Le Réseau Routier Inca de la Cordillère de Vilcabamba (Département de Cusco, Pérou): Description, Organisation, Origines et Fonctions. Tesis de doctorado, Université Paris 1 Panthéon-Sorbonne.
Durston, A. y J. Hidalgo 1997. La presencia andina en los valles de Arica, siglos XVI-XVIII: casos de regeneración colonial de estructuras archipielágicas. Chungara 29:249-273.

Duviols, P. 1966. La visite des idolâtries de Concepción de Chupas (Pérou, 1614). Journal de la Société des Américanistes 55:497-510.

- - - 1967. Un inédit de Cristóbal de Albornoz : la instrucción para descubrir todas las guacas del Pirú y sus camayos y haziendas. Journal de la Société des Américanistes 56:7-39.

- - - 1971. La lutte Contre les Religions Autochtones dans le Pérou Colonial, l'Extirpation de l'Idolâtrie entre 1532 et 1660. Institut Français d'Etudes Andines, Lima.

Espinoza Soriano, W. 1987. Migraciones internas en el reino colla: tejedores, plumereros y alfareros del estado imperial inca. Chungara 19:243-289.

Estete, M. 1891 [1534]. La relación del viaje qui hizo el señor capitán Hernando Pizarro. En Verdadera Relación de la Conquista del Perú, editado por F. Xérez, pp. 119-149. Cayetano Garcia, Madrid.

Falcón, F. 1867 [1567]. Representación hecha por el licenciado Falcón en concilio provincial sobre los daños y molestias que se hacen a los indios. En Colección de Documentos Inéditos Relativos al Descubrimiento, Conquista y Organización de las Antiguas Posesiones Españolas de América y Oceanía, Tomo VII, editado por L. Torres de Mendoza, pp. 451-495. Ministerio de Ultramar, Madrid.

Favre, H. 1967. Tayta Wamani. Le culte des montagnes dans le Centre Sud des Andes péruviennes. Colloque d'Études Péruviennes, Publications des Annales de la Faculté des Lettres Aix-en-Provence, Editions Ophrys, pp. 121-140.

Fernández de Oviedo, G. 1959 [1550]. Historia General y Natural de las Indias. Biblioteca de Autores Españoles, Tomo CXXI, Madrid.

Garcilaso de la Vega, I. 1959 [1609]. Comentarios Reales de los Incas. Librería Internacional del Perú, Peuser, Buenos Aires.

Gisbert, T. 1994. El señorío de los carangas y los chullpares del río Lauca. Revista Andina 12:427-485.

González Carré, E., D. Pozzi-Escot, M. Pozzi-Escot y C. Vivanco Pomacanchari 1987. Los Chankas: Cultura Material. Universidad Nacional de San Cristóbal de Huamanga, Ayacucho.

González Holguín, D. 1608. Vocabulario de la Lengua General de todo el Perú Llamada Lengua Qquichua o del Inca. Editado por F. del Canto, Lima.

Guaman Poma de Ayala, F. 1936 [1613]. Nueva Corónica y Buen Gobierno. Editado por R. Pietschmann. Travaux et Mémoires de l'Institut d'Ethnologie, XXIII, Institut d'Ethnologie, Paris.

Guillén Guillén, E. 1962. El ttocricuk y el tucuyricuc en la organización política del imperio incaico. En Actas y Trabajos del II Congreso Nacional de Historia del Perú, Vol. II, pp. 157203. Centro de Estudios Histórico-Militares del Perú, Lima.

Hidalgo, J. y G. Focacci 1986. Multietnicidad en Arica, siglo XVI. Evidencias etnohistóricas y arqueológicas. Chungara 16-17:137-147.

Horta, H. 2010. El Señorío Arica y los Reinos Altiplánicos: Complementariedad Ecológica y Multietnicidad Durante los 
Siglos Pre-Conquista en el Norte de Chile (1000-1540 d.C.). Tesis doctoral, Universidad de Chile, Santiago.

Hyslop, J. 1976. An Archaeological Investigation of the Lupaca Kingdom and its Origins. Ph.D. Dissertation, Columbia University, New York.

- - - 1984. The Inka Road System. Academic Press, Orlando.

- - - 1992 [1984]. Qhapaqñan, el Sistema Vial Inkaiko. Traducido por E. Mujica. Instituto Andino de Estudios Arqueológicos, Petróleos del Perú, Lima.

Itier, C. 2004. La Littérature Orale Quechua de la Région de Cuzco, Pérou. Karthala, Langues O', Paris.

Julien, C. 1985. Guano and resource control in sixteenth century Arequipa. En Andean Ecology and Civilization: An Interdisciplinary Perspective on Andean Ecological Complementarity, editado por S. Masuda, I. Shimada y C. Morris, pp. 185-231. University of Tokyo Press, Tokyo.

Lavallée, D. y M. Julien 1973. Les Etablissements asto a L'Époque Préhispanique. Travaux de l'Institut Français d'Etudes Andines, Tomo 15, Lima.

Lecoq, P. 1999. Uyuni Prehispanique, Archeologie de la Cordillere Intersalar (Sud-Ouest Bolivien). BAR, International Series 798, Oxford.

Leoni, J. 2005. La veneración de montañas en los Andes preincaicos: el caso de Nawinpukyo (Ayacucho, Perú) en el Período Intermedio Temprano. Chungara Revista de Antropología Chilena 37:151-164.

Lizárraga, R. 1987 [1607]. Descripción del Perú, Tucumán, Río de la Plata y Chile. Editado por I. Ballesteros. Historia 16, Crónicas de América 37, Madrid.

López de Gómara, F. 1946 [1552]. Historia General de las Indias. Calpe, Madrid.

Martínez, G. 1976. El Sistema de los Uywiris en Isluga. Universidad del Norte, Antofagasta.

- - - 1983 Los dioses de los cerros en los Andes. Journal de la Société des Américanistes 69:85-115.

Matienzo, J. 1967 [1567]. Gobierno del Perú (1567). Editado por G. Lohmann Villena. Travaux de l'Institut Français d'Etudes Andines, Tome 11, Lima.

Meddens, F. 1997. Function and meaning of the usnu in Late Horizon, Peru. Tawantinsuyu 3:4-14.

Michel, M. 2000. El Señorío Prehispánico de Carangas. Diplomado superior en Derechos de los pueblos indígenas. Universidad de la Cordillera, La Paz.

Muñoz, I. 1989. Perfil de la organización económico-social en la desembocadura del río Camarones: períodos Intermedio Tardío e Inca. Chungara 22:85-111.

- _ - 2005a. Espacio social y áreas de actividad en asentamientos agrícolas prehispánicos tardíos en la sierra de Arica. Bulletin de l'Institut Français d'Etudes Andines 34:321-355.

- - - 2005b. Manejo de recursos y coexistencia poblacional en la quebrada de Cobija durante la influencia inca. Estudios Atacameños 29:97-123.

- - - 2007. Caillama: organización del espacio doméstico y áreas de actividad en un asentamiento prehispánico de altura, período Intermedio Tardío Norte de Chile. Chungara Revista de Antropología Chilena 39:259-283.

Muñoz, I. y L. Briones 1998. Poblados, rutas y arte rupestre precolombinos de Arica: descripción y análisis de sistema de organización. Chungara 28:47-84.

Muñoz, I. y J. Chacama 2006. Complejidad Social en las Alturas de Arica: Territorio, Etnicidad y Vinculación con el Estado Inca. Ediciones Universidad de Tarapacá, Arica, Chile.

Muñoz, I., J. Chacama, G. Espinosa y L. Briones 1987. La ocupación prehispánica tardía de Zapahuira y su vinculación a la organización económica y social inca. Chungara 18:67-89.

Murra, J. 1956. The Economic Organization of the Inca State. $\mathrm{Ph} . \mathrm{D}$. Dissertation, University of Chicago, Chicago.

- - - 1972. El control vertical de un máximo de pisos ecológicos en la economía de las sociedades andinas. En Visita de la Provincia de León de Huánuco en 1562, editado por J. Murra, pp. 427-476. Universidad Nacional Hermilio Valdizan, Huánuco.

Murúa, M. 1987 [1611]. Historia General del Perú. Historia 16, Madrid.

Nielsen, A. 2000. Andean Caravans: An Ethnoarchaeology. $\mathrm{Ph}$.D. Dissertation, University of Arizona, Tucson.

Niemeyer H. y V. Schiappacasse 1981. Aportes al conocimiento del período Tardío del extremo norte de Chile: análisis del sector Huancarane del valle de Camarones. Chungara 7:3-103.

Núñez, L. 1976. Geoglifos y tráfico de caravanas en el desierto chileno. En Homenaje al Dr. Gustavo Le Paige, editado por H. Niemeyer, pp. 147-201. Universidad del Norte, Santiago.

Núñez, L. y T. Dillehay 1995. Movilidad Giratoria, Armonía Social y Desarrollo en los Andes Meridionales: Patrones de Tráfico e Interacción Económica. Universidad Católica del Norte, Antofagasta.

Pärssinen, M. 2003. Tawantinsuyu, el Estado Inca y su Organización Politíca. Instituto Francés de Estudios Andinos, Fondo Editorial de la Pontificia Universidad Católica del Perú, Embajada de Finlandia, Lima.

Pizarro, P. 1944 [1571]. Relación del Descubrimiento y Conquista de los Reinos del Perú. Editado por E. Morales. Futuro, Buenos Aires.

Platt, T., T. Bouysse-Cassagne y O. Harris 2006. Qaraqara-Charka. Mallku, Inca y Rey en la Provincia de Charcas (Siglos XV-XVII). Historia Antropológica de una Confederación Aymara. Instituto Francés de Estudios Andinos, Plural Editores, University of St Andrews, University of London, Inter American Foundation, Fundación Cultural del Banco Central de Bolivia, La Paz.

Ramos Gavilán, A. 1988 [1621]. Historia del Santuario de Nuestra Señora de Copacabana. Editado por I. Prado Pastor, Lima.

Regal, A. 1936. Los Caminos del Inca en el Antiguo Perú. Sanmarti, Lima.

Reinhard, J. 2002. A high altitude archaeological survey in northern Chile. Chungara Revista de Antropología Chilena 34:85-99.

Reinhard, J. y J. Sanhueza 1981. Expedición "santuarios de altura y arqueología del altiplano". Manuscrito en posesión de los autores.

Riso Patrón, L. 1924. Diccionario Jeográfico de Chile. Imprenta Universitaria, Santiago. 
Rivière, G. 1982. Sabaya: Structures Socio-Economiques et Représentations Symboliques dans le Carangas, Bolivie. Tesis de doctorado, Ecole des Hautes Etudes en Sciences Sociales, Paris.

Romero, A. 2003 Chullpas de barro, interacción y dinámica política en la precordillera de Arica durante el período Intermedio Tardío. Textos Antropológicos 14:83-103.

Rostworowski, M. 1977. Etnia y Sociedad: Costa Peruana Prehispánica. Instituto de Estudios Peruanos, Lima.

Santillán, H. 1968 [1560]. Relación del origen, descendencia, política y gobierno de los Incas. En Crónicas Peruanas de Interés Indígena, editado por F. Esteve Barba, pp. 97-149. Biblioteca de Autores Españoles, Tomo CCIX, Atlas, Madrid.

Santo Tomás, D. 1951 [1560]. Lexicón o Vocabulario de la Lengua General del Perú. Editado por R. Porras Barrenechea. Universidad Nacional Mayor de San Marcos, Instituto de Historia, Lima.

Santoro, C. 1983. Camino del Inca en la sierra de Arica. Chungara 10:47-56.

Santoro, C. e I. Muñoz 1981 Patrón habitacional incaico en el área de Pampa Alto Ramírez (Arica, Chile). Chungara 7:144-171.

Sarmiento de Gamboa, P. 2001 [1572]. Historia de los Incas. Editado por R. Alba. Miraguano Ediciones, Ediciones Polifemo, Madrid.

Schiappacasse, V. y H. Niemeyer 1997. Continuidad y cambio cultural en el poblado actual, colonial e inca de Pachica, quebrada de Camarones. Chungara 29:209-247.

- - - 2002. Ceremonial inca provincial: el asentamiento de Saguara (cuenca de Camarones). Chungara Revista de Antropología Chilena 34:53-84.

Schjellerup, I. 2005. Incas y Españoles en la Conquista de los Chachapoya. Pontificia Universidad Católica del Perú, Fondo Editorial, Institut Français d'Etudes Andines, Lima.

Sepúlveda, M., A. Romero y L. Briones 2005. Tráfico de caravanas, arte rupestre y ritualidad en la quebrada de Suca (Extremo Norte de Chile). Chungara Revista de Antropología Chilena 37:225-243.

Stehberg, R. 2001. Los caminos inka en Chile. En Tras la Huella del Inka en Chile, editado por C. Aldunate y L. Cornejo, pp. 92-103. Museo Chileno de Arte Precolombino, Santiago.
Taylor, G. 1980. Supay. Amerindia 5:47-63.

Toledo, F. 1986. Francisco de Toledo: Disposiciones Gubernativas para el Virreinato del Perú. 1575-1580. Editado por G. Lohmann Villena. Escuela de Estudios Hispano-Americanos, Monte de Piedad y Caja de Ahorros de Sevilla, Sevilla.

Topic, J. y T. Topic 1997. Hacia una comprensión conceptual de la guerra andina. En Homenaje a Maria Rostworowski, editado por R. Varón Gabai y J. Flores Espinoza, pp. 567-590. Instituto de Estudios Peruanos, Banco Central de Reserva del Perú, Lima.

Torres-Rouff, C., M. Costa-Junqueira y A. Llagostera 2005. Violence in times of change: The Late Intermediate Period in San Pedro de Atacama. Chungara Revista de Antropología Chilena 37:75-83.

Uribe, M. 2006. Acerca de complejidad, desigualdad social y el complejo cultural Pica-Tarapacá en los Andes Centro-sur (1000-1450 DC). Estudios Atacameños 31:91-114.

Vaca de Castro, C. 1908 [1543]. Ordenanzas de tambos, distancia de unos a otros, modo de cargar a los indios y obligaciones de las justicias respectivas. Hecho en el Cuzco el 31 de mayo 1543. Revista Histórica 3:427-492.

Vázquez de Espinosa, A. 1969 [1628]. Compendio y descripción de las Indias Occidentales. Biblioteca de Autores Españoles, Tomo CCXXXI, Madrid.

Vivar, J. 2001 [1558]. Crónica de los Reinos de Chile. Editado por A. Barral Gómez. Crónicas de América 21, Dastin, Madrid.

Wachtel, N. 1971. La Vision des Vaincus. Les Indiens du Pérou Devant la Conquête Espagnole, 1530-1570. Editions Gallimard, Paris.

Ziólkowski, M. 2008. Coropuna y Solimana: los oráculos de Condesuyos. En Adivinación y Oráculos en el Mundo Andino Antiguo, editado por M. Curatola y M. Ziólkowski, pp. 121-159. Pontificia Universidad Católica de Lima, Instituto Francés de Estudios Andinos, Lima.

Zuidema, R. 1973. Kinship and ancestorcult in three peruvian communities. Hernandez Principe's account of 1622. Bulletin de l'Institut Français d'Etudes Andines 2:16-33.

-- - 1989. Reyes y Guerreros, Ensayos de Cultura Andina. Grandes Estudios Andinos, Fomciencias, Lima.

\section{Notas}

1 Según Bertonio (1612:92) chullpa designa un "entierro o serón donde metían sus defuntos" o un "serón como isanga donde ponían el difunto”. El lingüista César Itier (2004:21) precisa la etimología de la palabra chullpa. Significa "marchitado" y deriva del lexema chullu: "quitar su vigor o su consistencia". Así que el término chullpa designaba en realidad el estado del cuerpo del difunto. Guaman Poma de Ayala (1936 [1613]:287) indica que las torres funerarias se llamaban pucullo o ayanotapa. Bertonio $(1612: 34,282)$ señala lo siguiente: "callca: sepultura de piedras debaxo de tierra para los principales; cala phutti: sepulcro; cala callca: la bouedilla donde se enterrauan los indios y oy día lo usan".
2 Los mitmaqkuna eran individuos desplazados por los incas para fines económicos, políticos, militares o religiosos. Los incas desplazaban poblaciones cualquiera que sea la distancia, incluso adentro de un mismo grupo étnico o de una misma comunidad (Garcilaso de la Vega 1959 [1609]:371-374; Ramos Gavilán 1988 [1621]:84-85; Espinoza Soriano 1987:269).

3 Un guaca o huaca era un elemento del paisaje, un edificio, un individuo, un animal o un mineral sagrado al cual las poblaciones andinas rendían culto con ofrendas y sacrificios (Cobo 1964[1653]II:169-186). La pacarina (o pacarisca) era el lugar de origen mítico de los grupos prehispánicos andinos (cerro, roca, cueva, laguna, río, fuente, árbol...) (Duviols 1967:20). 
4 Cobo (1964 [1653]II:114) indica lo siguiente: “...ponía el inca en cada provincia un gobernador o virrey el cual era persona de autoridad y de ordinario deudo suyo cercano o muy privado; este se llamaba tocricuc..”.. Cobo precisa que el tocricuc tenía la "facultad de levantar gente y formar éjercito (...) salía a visitar el distrito a sus tiempos; hacía recoger los tributos y rentas reales y ponerlos en los depósitos, bastecer los tambos y empadronar los que nacían el año y los que entraban en edad de tributar (...) En suma este virrey velaba sobre los señores y caciques inferiores y les iba a la mano en lo que solían exceder (...) y procuraba saber cuanto sucedía en su provincia para proveer de remedio donde fuese menester". En el diccionario de quechua de Santo Tomás (1951 [1560]:142, 366), se lee "gobernación: tocrinin; gobernador: tocricoc; tocriconi: administrar officio; tocrini: muñir gente haziendo llamamiento". Bertonio (1612:360) indica en aymara: "thokhritha camachitha vel micchuatha: gouernar gente; thokhristha camachistha: idem y es más propio; thokhriri vel thokhrisri: gouernador de pueblos". ww. No se debe confundir el tocricuc y el tucuyricuc. En quechua tucuy significa "todo" y ricuc "él que mira" (Falcón 1867 [1567]:464; González Holguín 1608:315,346), entonces el tucuyricuc es "él que mira todo". En un estudio, Cerrón Palomino (2006) confirma que las palabras tocricuc y tucuyricuc tienen efectivamente una etimología diferente. En la administración inca, los tисиугісис eran inspectores desempeñando varios oficios encargados de controlar periódicamente la buena gestión de las provincias (Anónimo 1906:152; Bandera 1920 [1557]:68; Santillán 1968 [1560]:107-108; Guillén Guillén 1962).

5 A la lectura de numerosas publicaciones podemos constatar que muchos investigadores utilizan la palabra usnu para denominar las plataformas. Cristóbal de Albornoz (Duviols 1967:24), eclesiástico especialista de las prácticas religiosas de la poblaciones andinas nos da una definición bastante clara de lo que era un usnu: "Hay otra guaca general en los caminos reales y en las plaças de los pueblos que llamans uznos. Eran de figura de un bolo hecho de muchas diferencias piedras o de oro y de plata. A todos les tenían hechos edificios en donde tengo dicho en muchas partes como en Bilcas y en Pucara y en Guanaco el Viejo y en Tiaguanaco a hechura de torres de muy hermosa cantería. Sentavanse los señores a bever a el sol en el dicho uzno y hazían muchos sacrificios a el sol”. Por su lado, el Anónimo (1906:151) señala que el usnu tenía funciones astronómicas. Además, a veces un sistema de canales se encontraba en los usnu para drenar los líquidos (chicha, agua, sangre) ofrecidos durante las ceremonias (Zuidema 1989:402-454; Meddens 1997). En los diccionarios coloniales se puede leer: "ozno o osno: altar o ara para sacrificar; osno o cocongapac: altar donde sacrifican" (Santo Tomás 1951 [1560]:332). González Holguín (1608:360) indica lo siguiente: "usnu: tribunal de juez de una piedra hincada; usnu: mojón quando es de piedra grande hincada; usnuni: hazer los tribunales o mojones". Fuera de los susodichos elementos, el usnu simboliza el poder y la dominación inca sobre las poblaciones conquistadas reunidas en la plaza al pie de la plataforma donde estaba(n) el soberano inca o sus delegados. Pensamos que en algunas publicaciones científicas se utiliza la palabra usnu de manera abusiva para calificar cualquier tipo de plataforma y que durante la época inca todas las plataformas no eran del tipo usnu. Por otro lado, cabe señalar que los usnu de los centros administrativos incas no son similares en términos de arquitectura, dimensiones y orientación de las escaleras de acceso: él de Vilcahuaman es diferente de los de Huanucopampa, Pumpu o El Shincal por ejemplo. Existían probablemente plataformas con usos y funciones que podían variar según los lugares y la ubicación de cada plataforma en la geografía sagrada de cada zona y de cada región. Algunas plataformas, ubicadas en los centros administrativos a lo largo de las vías importantes, eran plataformas de tipo usnu según la definición de dicho término en las fuentes escritas coloniales. Desde nuestro punto de vista una plataforma ubicada en la plaza de un sitio en terreno llano (i.e usnu) no tiene la misma dimensión simbólica que una plataforma aislada edificada en una línea de cresta con una vista panorámica amplia sobre el paisaje sagrado. Sugiriendo la prudencia, pensamos que las plataformas ubicadas en lugares aislados (ausencia de la plaza en el medio de un pueblo), lejos de las vías importantes, no eran иsnu. Nuestros trabajos sobre la red vial prehispánica de la cordillera de Vilcabamba (Duffait 2007) nos inclinan a pensar que existía un tipología de plataformas con usos diferentes. Además, es importante preguntarse si todas las plataformas encontradas en lugares altos y aislados han sido construidas bajo el mando de los incas (siglos XV-XVI). Antes de las conquistas incas posiblemente ya existían algunas. Las excavaciones arqueológicas de las plataformas y el análisis de los artefactos deberían darnos precisiones en cuanto al origen y la antigüedad de este tipo de edificio sagrado. Existen usnu anteriores a la época inca en la cordillera de los Andes. Podemos mencionar los dos famosos usnu de Tiahuanaco (siglos I-XI d.C.) que son posiblemente los más grandes del mundo prehispánico andino: los edificios llamados Akapana y Pumapuncu. Conformadas por terrazas superpuestas y por un patio hundido en su cima, estas dos construcciones poseen además un sistema de drenaje muy complejo (Berenguer 2000:7-9,21-23). Es muy probable que los incas se hayan inspirado en el Akapana y en el Pumapuncu para edificar usnu durante su dominio en los Andes.

6 Por ejemplo, desde la época colonial la palabra supay significa "demonio" (González Holguín 1608:80). Sin embargo, como lo demostró Taylor (1980), supay designaba originalmente a la sombra -el doble del cuerpo humano de los muertos.

7 Los pueblos de reducción han sido creados en los siglos XVI y XVII a fin de alejar los grupos de sus tierras y de su pacarina, para controlar y cristianizar a la gente y percibir más fácilmente el tributo (Duviols 1971:248-256). 
